\title{
Fire Whirl Evolution Observed during a Valley Wind-Sea Breeze Reversal
}

\author{
Daisuke Seto and Craig B. Clements \\ Department of Meteorology and Climate Science, San José State University, San José, CA 95192, USA \\ Correspondence should be addressed to Craig B. Clements, craig.clements@sjsu.edu
}

Received 29 December 2010; Revised 4 April 2011; Accepted 27 April 2011

Academic Editor: William E. Mell

Copyright (๑) 2011 D. Seto and C. B. Clements. This is an open access article distributed under the Creative Commons Attribution License, which permits unrestricted use, distribution, and reproduction in any medium, provided the original work is properly cited.

\begin{abstract}
This observational study documented the atmospheric environment of a prescribed fire conducted in a narrow valley when a small fire whirl developed during a mesoscale wind reversal. Based on analysis of in situ meteorological measurements, it is hypothesized that the fire whirl formed due to the presence of strong vertical wind shear caused by the interaction of a sea breeze front with a weaker up-valley wind. Vorticity generated by the interaction of the wind shear and the fire front was estimated to be $\sim 0.2 \mathrm{~s}^{-1}$. Peak turbulence kinetic energy was caused by the wind shear rather than the buoyancy generated by the fire front. It was also found that the convective Froude number itself may not be sufficient for fire whirl prediction since it is less relevant to the nearsurface boundary-layer turbulence generated by environmental wind shear. Observations from this case study indicate that even low-intensity prescribed fires can result in the formation of fire whirls due to mesoscale changes in the ambient atmospheric environment.
\end{abstract}

\section{Introduction}

Wildland fire is a physical process that responds to variations in fuels, topography, and weather. The complex interactions between these can occasionally result in extreme fire behavior. Extreme fire behavior defined by National Interagency Fire Center implies a level of fire behavior characteristics that would make a fire difficult to control and involves one or more of the following: high rate of spread, prolific crowning and/or spotting, presence of fire whirls, and a strong convection column. Extreme fire behavior can result in compromised fire fighter safety and increased danger to communities. One of the fascinating phenomena of extreme fire behavior is fire whirls. Forthofer et al. [1] define fire whirls as vertically oriented, rotating columns of air found in or near fires. Fire whirls are often associated with extreme meteorological conditions and fire-atmosphere interactions. Fire whirls can transport fire far beyond the fire front, and they can also spread flames vertically. Graham [2] observed a fire whirl that became violent enough to break off trees at their bases.

Several environmental factors impact the formation of fire whirls including vorticity, atmospheric stability, and topography. Environmental vorticity can be produced in the atmosphere by vertical wind shear forming eddies and rotation of the surface air [3]. Umscheid et al. [4] observed and photographed a large fire whirl that lasted for about 20 minutes and occurred during a slow moving cold front where pre-existing environmental vertical vorticity interacted with a wheat stubble field burn causing the fire whirl development.

Atmospheric instability is a favorable condition for fire whirl development because strong updrafts produced by an unstable atmosphere itself can start fire whirls [3]. However, Byram [5] points out that it is an entirely normal condition for large fires to cause warmer air below cooler air and fire whirls are only present where the atmosphere is in particular unstable conditions and thus, there must be some conditions other than instability by heating to cause their formation.

Fires on steep lee slopes present a favorable situation for fire whirls to develop [1,3]. Graham [6] observed 28 fire whirls that formed in mountainous terrain and reported that 20 of the fire whirls formed on lee slopes. The ridge acts as an obstruction to airflow, causing mechanically induced eddies on the lee side. The lee side of the slope is an ideal location for the convergence of the upslope flow of hot gases and the cool opposing ambient wind crossing the ridge potentially 
leading to strong wind shear. An observation of a destructive fire whirl by Pirsko et al. [7] suggests that channeled drainage flows in steep canyons are conductive to turbulent winds. Forthofer et al. [1] also suggested flow channeling in complex terrain as a potential source of vorticity. The topographic effects on the fire whirl formation are often mentioned as a primary cause of fire whirls $[6,8]$.

In previous studies, a concentrating mechanism has been suggested as a source of fire whirl formation $[1,3$, $9,10]$. Buoyancy generated by the fire acts to converge nearby ambient eddies and vorticity, triggering the fire whirl formation. Tilting and stretching of horizontal vorticity most likely occurs above the flaming front, since hot gasses from the fire generate strong buoyant forcing. Occasionally, fire whirls are observed downstream of fire plumes as depicted by Fric and Roshko [11]. Clark et al. [12] describe the formation of a near-surface convergence zone ahead of the fire line as a result of the hydrostatic pressure gradient caused by the tilted plume and air being drawn into the convection column. The existence of the downwind convergence zone was verified by Clements et al. [13] who measured the weak convergence of winds ahead of the fire front using in situ tower measurements during an intense grass fire that generated a large fire whirl downstream of the fire front [14]. Additionally, Hanley et al. [15] found that the arrival of a sea breeze front during a wildfire resulted in a temporary increase in fire intensity as a result of enhanced convergence and vertical motion which could potentially lead to fire whirl formation.

There appears to be similarity in the conditions in which fire whirls and dust devils form, such as atmospheric instability and low-level wind shear. Smaller fire whirls are also comparable in size to dust devils that typically range from 6 to $60 \mathrm{~m}$ in diameter [16]. Bluestein et al. [17] used a Doppler radar to measure the vorticity in a dust devil core. They showed the measured vorticity was similar to that in some tornadoes, but the maximum wind velocity of the dust devils was much weaker. The main difference between fire whirls and dust devils is that fire whirls maintain the rotating column from buoyancy generated by the combustion of the fire, whereas dust devils rely on the intense surface heating from insolation as a source of potential energy.

While fire whirls have been observed during a number of wildland fires, few observational studies have succeeded in measuring both the in situ atmospheric environment and fire behavior simultaneously, thus the understanding of their dynamics is not well understood. In this paper, observations made during the interaction of a valley wind reversal and grass fire are explored to investigate the causes of fire whirl formation. In addition, the convective Froude number, ambient turbulence kinetic energy, and resulting fire behavior are analyzed and compared with previous studies.

\section{Experimental Design}

2.1. Site Description. The observational campaign was conducted during a vegetation management fire (prescribed burn) conducted by Cal Fire (California Department of Forestry and Fire Protection) on 7 October 2008 at Joseph D.

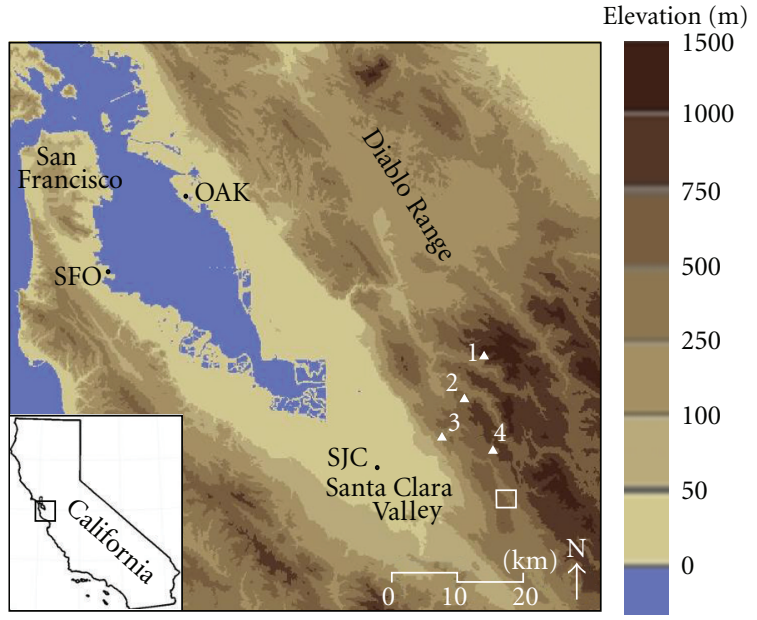

Figure 1: A map of San Francisco Bay Area to define the geographical locations of Joseph D. Grant County Park (box) and four nearby RAWS stations ((1) Rose Peak (RSPC1), (2) Poverty (MIPC), (3) Alum Rock (RJSC1), and (4) CDF portable 10 (TR098)). Major airports are also indicated for reference, San Francisco (SFO), Oakland (OAK), and San José (SJC) Elevation above mean sea level (MSL) is shaded according to the scale.

Grant County Park. The park is located in the Diablo Range approximately $6.5 \mathrm{~km}$ east of San José, California and $60 \mathrm{~km}$ east of the Pacific Ocean (Figure 1). The experimental site is located in the northwest-southeast oriented Hall's Valley, with a valley bottom elevation of $440 \mathrm{~m}$ MSL surrounded by ridges that rise $660 \mathrm{~m}$ on the west and $830 \mathrm{~m}$ on the east (Figure 2). The burn unit was $0.14 \mathrm{~km}^{2}$ (35 acres) in size, with fuels dominated by a mixture of grasses including Italian Rye (Lolium Multiflotun), Oat Grass (Avena Barbata), Soft Brome (Bromus Hordeaceus), and Purple Needle Grass (Nassella Pulchra). The soils were dry and fuels were fully cured. The estimated fuel loading was $0.12 \mathrm{~kg} \mathrm{~m}^{-2}$ (0.5 tons acre $\left.^{-1}\right)$.

2.2. Background Meteorology. The synoptic conditions on the day of the prescribed burn were warm and dry under the influence of a building high-pressure ridge over the eastern Pacific and a weak thermal trough in place over central California. A shallow layer of stratus confined to Santa Clara Valley below the ridge crests was observed early in the morning, but the stratus did not fill into the Hall's Valley site the previous night due to the topographic blocking. Nearby Remote Automated Weather Station (RAWS) temperature data supports that the cool marine air remained below $500 \mathrm{~m}$ MSL as indicated from the surrounding RAWS stations (Figure 3). For example, at the elevation of $223 \mathrm{~m}$ MSL the Alum Rock site was influenced by the marine layer, while the other nearby RAWS stations at elevations above $500 \mathrm{~m}$ MSL remained above the marine inversion overnight (Figure 3 ). The Oakland $12 \mathrm{Z}$ sounding (not shown), which is located $60 \mathrm{~km}$ north of site, also showed a moist surface layer below $500 \mathrm{~m}$ MSL along with weak northeast winds near the surface, indicating that the marine layer was below the ridge height and had not pushed further inland. 


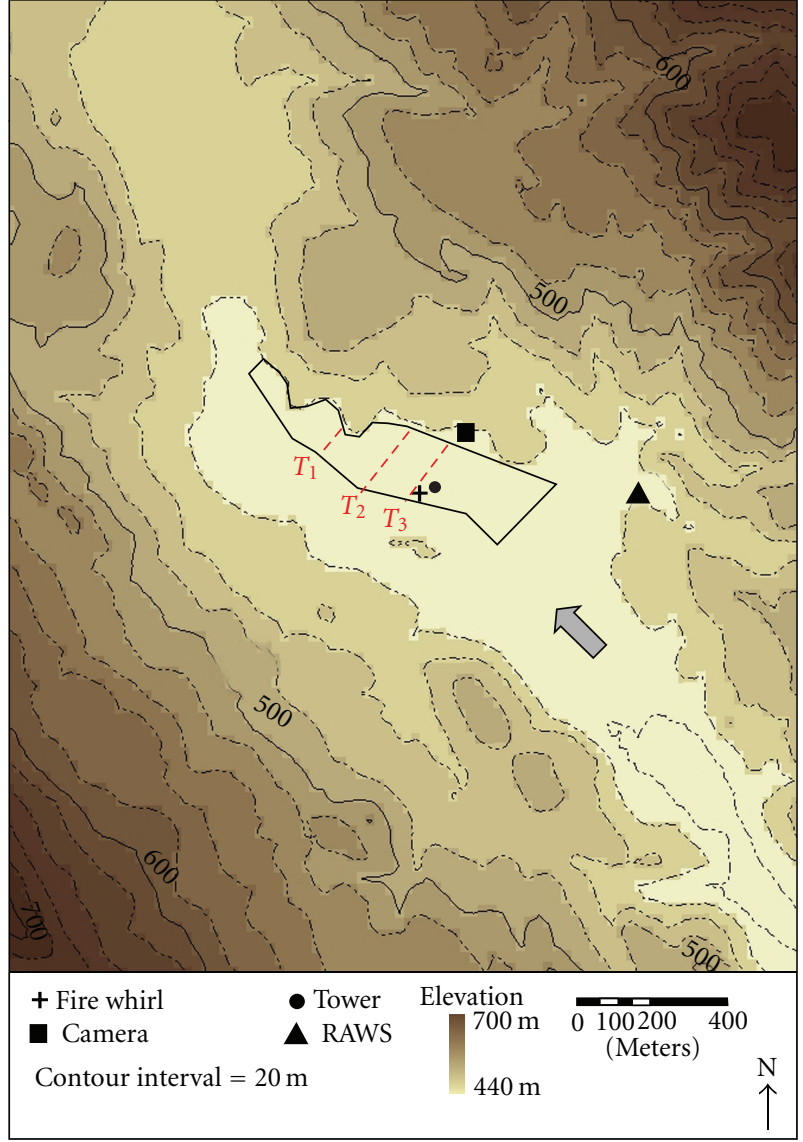

Figure 2: A map of the experiment site and instrument locations. The burn unit is indicated by the solid black line. The solid arrow indicates initial wind direction prior to the wind shift. The dashed red lines indicate approximate positions of the fire front: $T_{1}=11$ : $45, T_{2}=12: 30$, and $T_{3}=12: 42$.

In order to determine the ambient atmospheric stability and vertical wind profile at the valley site, a rawinsonde sounding was conducted on the valley floor $\sim 1 \mathrm{~km}$ north northwest of the burn unit, at 0800 PDT (Pacific Daylight Time). A shallow inversion layer near the surface to $500 \mathrm{~m}$ AGL is evident from the temperature profile (Figure 4(a)), and north to northeast winds within the layer are likely to be a combination of nocturnal down-valley and downslope winds (Figure 4(b)). Very stable atmospheric conditions and a clear sky were evident throughout the lower troposphere as indicated by the sounding. The sounding, however, does not represent the atmospheric environment during the ignition since the valley inversion broke before ignition.

\subsection{Instrumentation. The objective of the experiment was to} capture and characterize fire-atmosphere interactions during a grass fire using high-frequency measurements. In order to capture the micrometeorology of the passing fire front, a $6.7 \mathrm{~m}$ guyed, steel tower was deployed near the center of the burn unit and the fire front was allowed to burn directly beneath it (Figure 2). Fuels were removed $1.5 \mathrm{~m}$ from around the base of the tower in order to protect it from direct flame. The tower was equipped with a 3D sonic anemometer

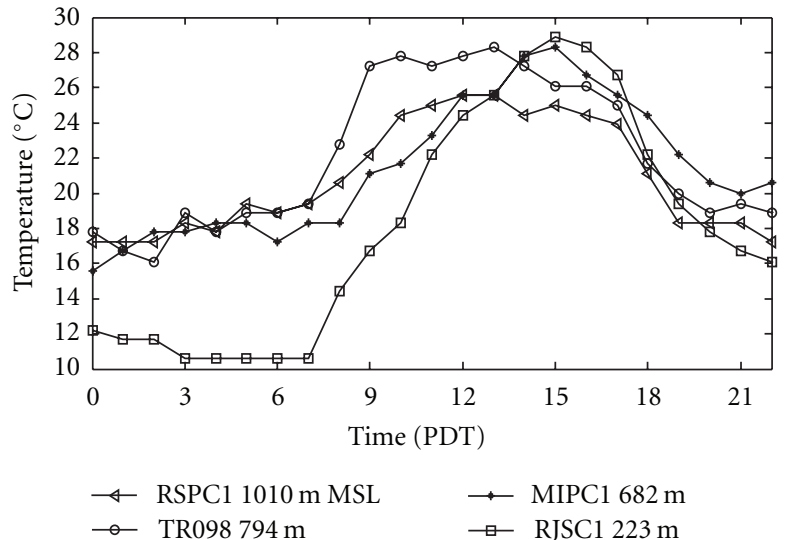

FIGURE 3: $60 \mathrm{~min}$ average temperatures recorded at nearby RAWS sites during the day of the burn. The relative locations of the RAWS stations are shown in Figure 1.

(Applied Technologies, Inc., Sx-probe) mounted to the tower at $6 \mathrm{~m} \mathrm{AGL}$, four type-T thermocouples (Omega, Inc. 5SCTT-40) mounted at 0.15, 2, 2.7, and $3.5 \mathrm{~m} \mathrm{AGL,} \mathrm{and} \mathrm{a}$ temperature and humidity sensor (Vaisala Inc. HMP45C) mounted at $2.5 \mathrm{~m}$ AGL. The sonic anemometer was sampled at $10 \mathrm{~Hz}$, while the thermocouples and temperature and humidity probe were sampled at $1 \mathrm{~Hz}$. Additionally, total heat flux emitted from the fire front was measured with a Schmidt-Boelter heat flux sensor (Hukseflux, SBG01) that was attached to a cross arm mounted on the tower at $5 \mathrm{~m}$ AGL and extending $1.5 \mathrm{~m}$ away from the tower horizontally. The sensor transducer was pointed down at a $45^{\circ}$ angle and outward towards the approaching fire front. The SBG01 was sampled at $10 \mathrm{~Hz}$. In order to determine the time the plume impinged on the tower and instrumentation, the concentration of $\mathrm{CO}_{2}$ in the smoke was sampled using a Vaisala Inc. GMP343 NDIR probe sampled at $1 \mathrm{~Hz}$. All tower data were recorded using a Campbell Scientific, Inc. (CSI) CR3000 datalogger mounted near the base of the tower housed in an environmental enclosure. Additionally, the datalogger and the base of the tower were protected from the intense heat generated by the fire using fireproof insulation wrapped around the lowest $2 \mathrm{~m}$ of the tower.

To document the atmospheric conditions occurring outside of the burn unit, a portable weather station was located downwind and approximately $150 \mathrm{~m}$ away from the southeast corner of the burn unit (Figure 2). A $3 \mathrm{~m}$ tripod was outfitted with a temperature and humidity probe (CSI, CS215), barometer (Vaisala Inc., PTB110), and a prop-vane anemometer (R. M. Young, 5103), all sampled at $1 \mathrm{~Hz}$ and stored as 1-minute averages using a CSI CR1000 datalogger. There was $2-3 \mathrm{~m}$ tall brush surrounding the site, making the downwind weather station site slightly less exposed to the ambient wind than the interior tower site.

Fire behavior including spread rate and evolution of the fire front was documented using a digital SLR camera (Canon, Inc. 40D) with a $1 \mathrm{~Hz}$ time lapse function. The camera clock was synchronized to the datalogger clocks so that the time lapse photography could be compared to the time series data for analysis. 


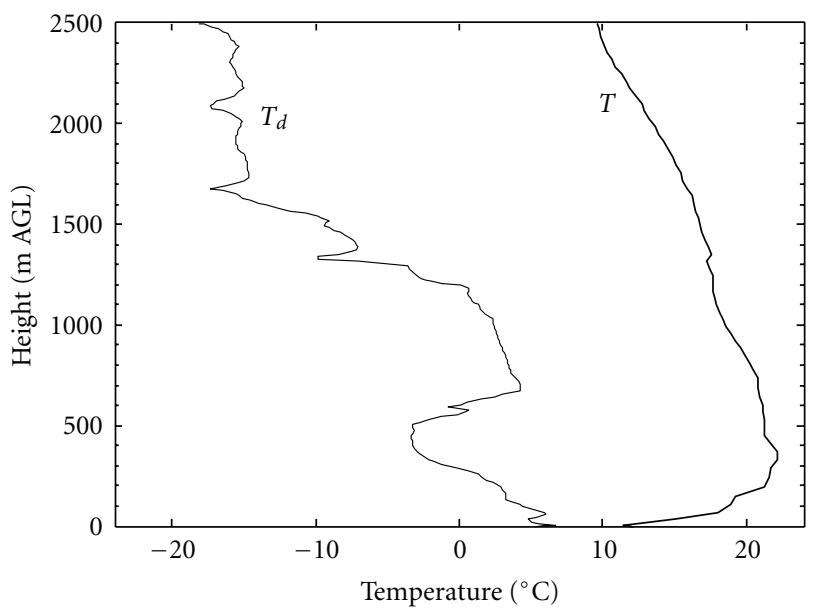

(a)

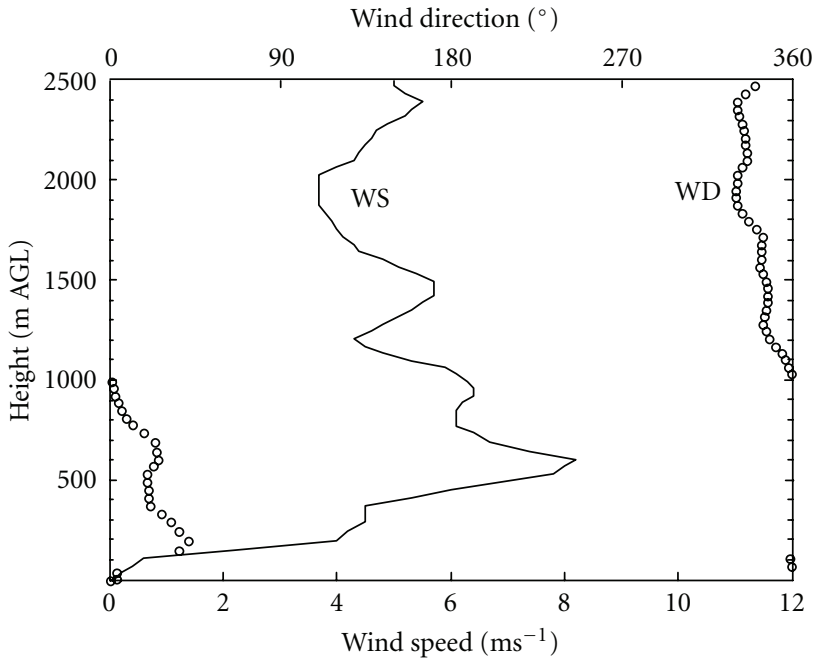

(b)

Figure 4: Vertical profiles of (a) air temperature $T$ and dew point temperature $T_{d}$ and (b) wind speed (WS) and wind direction (WD) at Stockman's Field ( $\sim 1.5 \mathrm{~km}$ north northwest of the burn unit) for the day of the burn, 7 October 2008 at 0800 PDT.

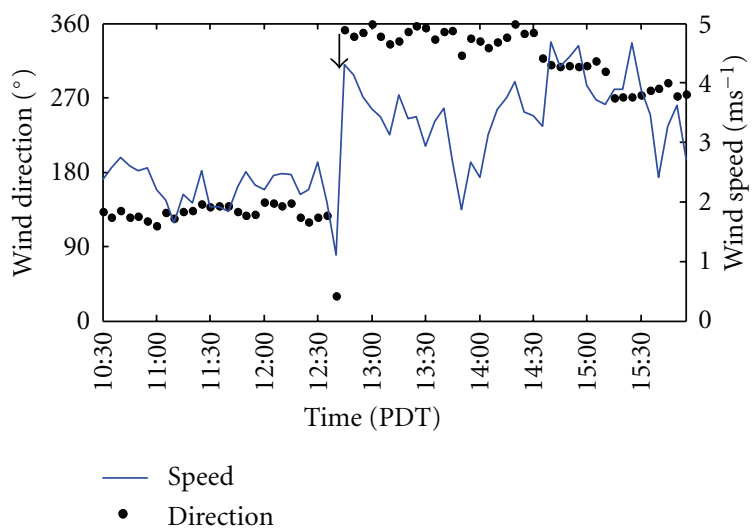

Figure 5: Time series of 5 min averaged wind speed and direction at the interior tower. Timing of fire whirl is indicated with solid arrow.

2.4. Burn Operations and Fireline Evolution. The goal of the prescribed fire was the eradication of invasive grass species; however, the site was populated with native oak species requiring low-intensity backing fires (fire moving opposite the wind direction) to be used in order to limit scorching of the oaks. The experimental plan was to take advantage of the burn operations and measure fire-atmosphere interactions during the grass fire. One specific goal was to determine the role of fine-scale fire-atmosphere interactions on fire behavior during the passage of a head fire (fire that propagates with the ambient wind) which required the burn crew to ignite a single line, head fire upwind of the instrument tower.

During the initial back burning, the wind was from the southeast, as an up-valley wind (Figure 5), so the back burning began on the northern edge of the burn plot (Figure 2, $T_{1}, T_{2}$ ). Once the back burning was completed, the burn crew began walking around the instrument tower to start a line ignition $100 \mathrm{~m}$ upwind (to the south) of the tower that would spread with the southerly wind and pass through the tower as a head fire. At this point (12:43 PDT), a $180^{\circ}$ wind shift occurred at the surface and the initial backing fire began to run as a head fire towards the tower (Figure 2, $T_{3}$ ). It was at this time that a fire whirl formed.

2.5. Evolution of Wind Reversal. The time series of 5minute average wind speed and direction from the interior tower (Figure 5) shows that weak $\left(<3 \mathrm{~ms}^{-1}\right)$ south and southeasterly winds prevailed in the valley and were the daytime up-valley winds that typically occur in mountain valleys $[18,19]$. By 12:45 PDT, the up-valley winds were replaced by a break-in of moderate $\left(2.0\right.$ to $\left.4.5 \mathrm{~ms}^{-1}\right)$ north to northwesterly flows associated with the sea breeze surge.

The evolution of the surface environment as the sea breeze arrived, as well as the timing of the fire whirl formation and dissipation, is shown in Figure 5. Prior to the fire whirl formation (12:42 PDT), a southerly component of the wind $\left(135^{\circ}-225^{\circ}\right)$ was observed at the tower location. The sea breeze arrival is indicated by the shift in wind direction and the increase in relative humidity at 12:43 PDT. It is interesting to point out that the first sign of the northnorthwest winds that dominate the valley afterward are apparent as the fire whirl dissipates, as if the intensifying northerly winds act as the cutoff source of the fire whirl. The in situ measured data reveals that a much more complicated flow pattern occurred in front of the fire line during the transition period. This will be discussed further in the following sections.

\section{Results and Discussion}

3.1. Fire Whirl Evolution. The fire whirl was observed approximately $35 \mathrm{~m}$ west of the interior tower (Figure 2) during the period when the winds shifted from southerly to northerly. The time lapse photos and recorded video images are visually analyzed, and they show that the cyclonically 
rotating fire whirl formed at one end of the flaming front where the most intense flame was present at that moment. Countryman [3] had previously noted that fire whirls form near the more intense region of the fire front. Figure 6 shows a time series of photos taken during the entire evolution of the fire whirl from its initial formation to dissipation. A $\sim 1 \mathrm{~m}$ wide, vertically rotating column of flame appeared within the fire front at 12:43:10 PDT (Figure 6(a)). We inferred from the sequence of the time lapse photos between Figures 6(a) and 6(b) (not shown) that the vorticity was already present within the flame by this time. The rotating column kept drawing the flame along the fire line into the base of the column (Figure 6(b)), while the flame height at this time reached $\sim 4 \mathrm{~m}$ AGL within the rotating column (Figure $6(\mathrm{c})$ ) before the flame disappeared altogether from the base of the fire whirl. This may have occurred because the near-surface flow converged parallel to the fire front and toward the base of the fire whirl (documented in the sequence of the photos as well as in video), limiting the ignition of the unburned fuel ahead of the fire front and the forward spread of the fire. Therefore, the flame was no longer supplied to the base of the fire whirl. Although the rotating column of smoke initially appeared within the fire line, the fully formed fire whirl was observed to move backward into the black area behind the fire front (Figure 6(d)). The fire whirl was still intensifying over the freshly burnt area (Figure 6(e)) behind the fire line without any active combustion indicating that the hot ground can provide a source of energy for its further development. A maximum vertical extent of approximately $200 \mathrm{~m}$ AGL was observed (Figure 7) once the fire whirl was fully formed (Figures 6(e) and 6(f)). A time series of the vertical velocity (Figure $8(\mathrm{~b})$ ) shows a positive velocity peak at 12:43:38 PDT, followed by negative vertical velocity lasting until 12:44:00 PDT. It is interesting to note that the timing of the downward motion observed at the tower occurred at the time the fire whirl dissipated. Since the tower was located $35 \mathrm{~m}$ away from the fire whirl, it cannot be assumed that the observed vertical velocity field is related to the evolution of the fire whirl. The horizontal wind speed also dropped to $0.4 \mathrm{~m} \mathrm{~s}^{-1}$ at this time (Figure 9(a)) indicating a transition period from one wind regime to another and a brief period of convergence. It was also observed that the fire whirl dissipated from its base (Figures $6(\mathrm{~g})$ and 7 ), while the rotation and smoke column was still present aloft (Figure 7). After the fire whirl dissipated at 12:44:00 PDT (Figure 6(h)), northerly flow observed at the tower started intensifying in velocity (Figures 9(a) and 9(b)), indicating the full onset of the sea breeze penetrating through the valley. It was observed that the intensified flow began driving the flaming front towards the tower as a head fire with a faster rate of spread. Time lapse photography indicated a forward-tilting flame front and smoke plume approaching the tower. Flame height increased as well with increasing ambient wind speed as compared with the flame height during the up-valley wind event. This dramatic change in fire behavior occurred over a period of only 2 minutes.

3.2. Evolution of the Observed Vorticity. The winds observed at the tower reveal a rather complex turbulence structure because of the presence of both the fire front and the interaction of the two opposing winds. Therefore, it only allows us to hypothesize what caused the vorticity formation in the valley. Over flat terrain, the leading edge of the sea breeze front, being a colder and more dense flow is generally forced upwards and backwards from the front by the opposing wind, creating Kelvin-Helmholtz billows along its interface with the opposing ambient wind $[20,21]$. The vertical shear associated with opposing flows can produce the so-called hyperbolic wind profile [12] at low levels leading to the development of horizontal vorticity aligned perpendicular to the wind direction. When this type of wind shear interacts with a fire line, a pair of near-surface vortices may develop in front of the fire line and eventually touch down in the fire due to advection as described by Jenkins et al. [22]. The rotating vortices are caused by the tilting of the horizontal vorticity into the vertical by the updrafts associated with the fire front. Their simulations also show that a constant ambient wind profile can produce vortices but well in front of the fire line. The close proximity of the vortices to the fire line may play a critical role in the development of the fire whirl such as in this case study, especially when fire is wind-driven and the surface wind drives the vortices well ahead of the fire line further downwind. In contrast, a moderate ambient wind decreasing slowly with height with weak vertical shear does not promote the extreme fire behavior as demonstrated by Jenkins et al. [23].

Further analysis of the time-lapse photography shows that the rotating column of the fire whirl, initially formed at the fire line, moved behind the fire line, which can be explained by either the advection of vorticity by the upvalley flow or from the development of a pressure perturbation/gradient that formed between the burnt area behind the fire front and the cooler air over the un-burnt area ahead of the fire front [12]. In the photographs of Figures 6(b)6(d), the fire whirl jumped from the fire line at 12:43:27 PDT (Figure 6(c)) northwestward by approximately $6 \mathrm{~m}$ to a point estimated in Figure 6(d) behind the fire line at 12:43:33 PDT. The wind direction at this time was $100^{\circ}$ with velocities of $1.5-2 \mathrm{~ms}^{-1}$ (Figures 9(a) and 9(b)) allowing the vorticity to advect over a period of 3-4 s.

Although the single-point-in-space tower measurements in this experiment do not directly provide enough parameters necessary to calculate the horizontal vorticity that is hypothesized to have formed at the fire line, it is possible to estimate the vorticity under several assumptions. The twodimensional relative vorticity field $\zeta$ described by Heilman [24] is defined as

$$
\zeta=\frac{\partial w}{\partial y}-\frac{\partial v}{\partial z}
$$

where $w$ is the vertical velocity and $v$ is the along-valley wind (sea breeze and up-valley wind) component that is perpendicular to the fire line. The instantaneous wind velocity components are shown between 12:40 and 12:46 PDT in Figure 8. We determined $\partial w / \partial y$ from (1) by comparing the vertical velocity measured directly at the fire front and well before the fire front passage (FFP) occurred with an 


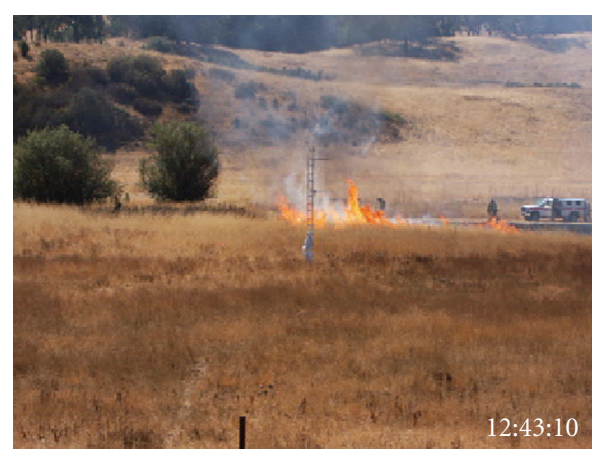

(a)

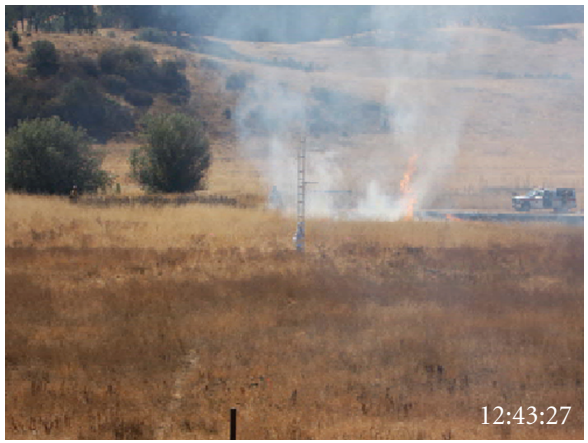

(c)

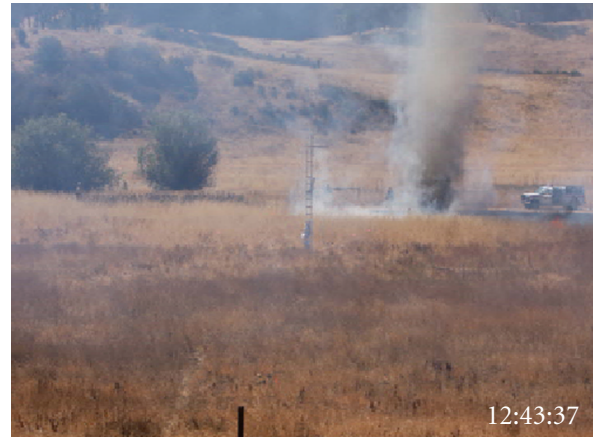

(e)

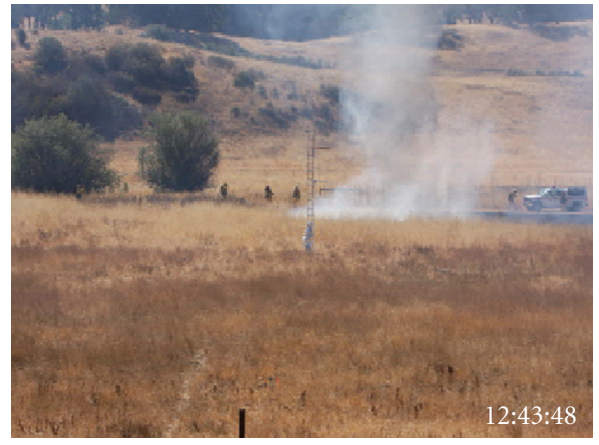

(g)

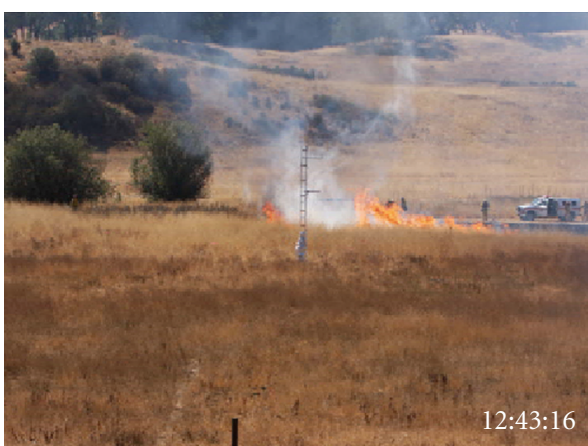

(b)

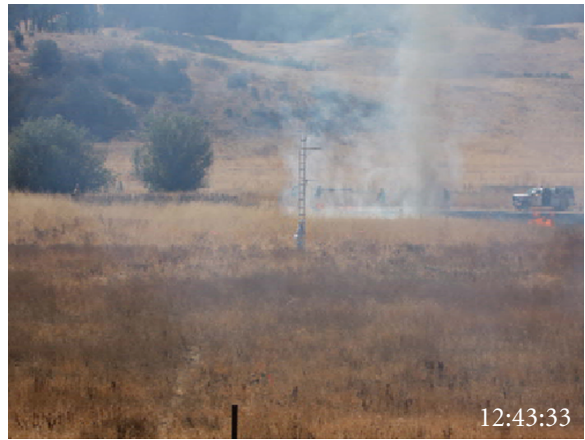

(d)

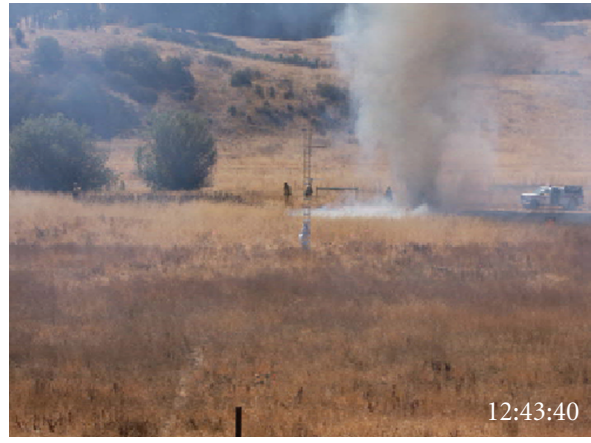

(f)

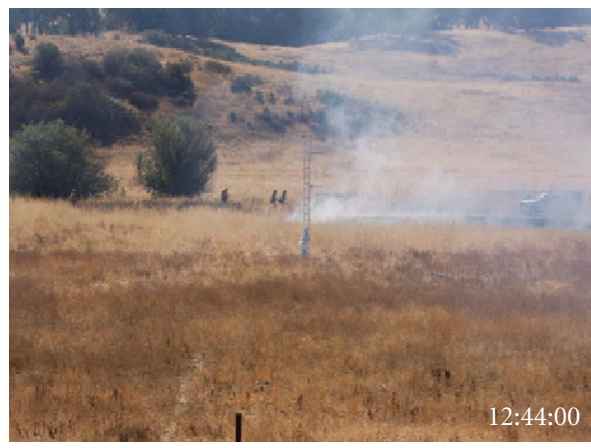

(h)

Figure 6: Time-lapse photographs of the fire whirl evolution during a valley wind reversal. Times are indicated in the bottom of each panel in PDT. 


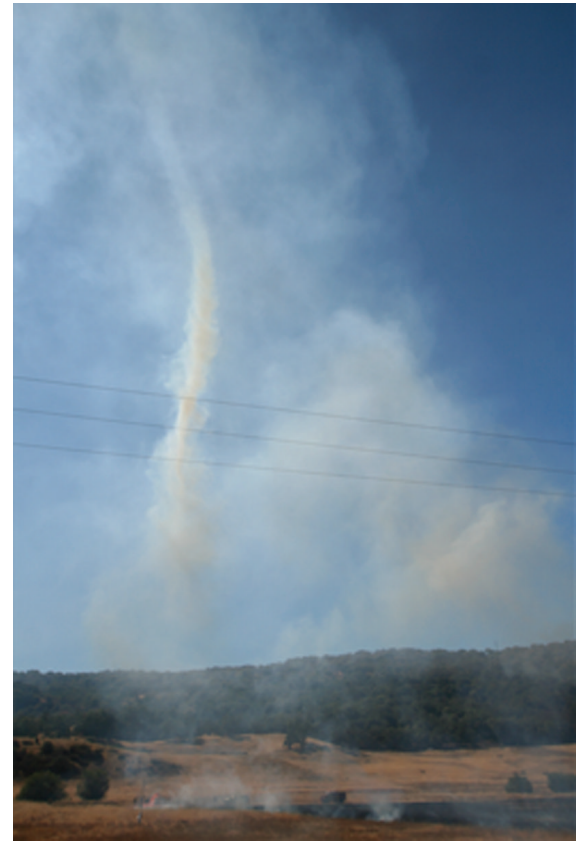

FIGURE 7: Photograph of dissipating fire whirl near the surface while rotating column is still active aloft (12:44 PDT). Tower can be seen in the bottom of the photograph.

estimated distance of $10 \mathrm{~m}$ (between the fire front and the tower). The FFP is defined by Clements et al. [14] as a maximum in the heat flux measured at the tower. It is the point where the fire front is closest to the tower as measured by the heat flux radiometers and peak in sensible heat flux from the sonic anemometers. The maximum observed vertical velocity associated with the fire front (Figure $8(\mathrm{~b})$ ) was $\sim 2.8 \mathrm{~ms}^{-1}$, while the ambient vertical velocity measured was $\sim 0.6 \mathrm{~ms}^{-1}$ resulting in an estimate for $\partial w / \partial y$ of $\sim$ $0.22 \mathrm{~s}^{-1}$. To determine $\partial v / \partial z$, we estimate the depth of the sea breeze front to be $\sim 200 \mathrm{~m}$ following observations by Simpson [20]. We determined the change in $v$ using the observed averaged along-valley wind velocities (Figure 8(a)). The up-valley wind of $1.1 \mathrm{~ms}^{-1}$ prior to the wind shift at 12:43 PDT and the sea breeze velocity of $-3.4 \mathrm{~ms}^{-1}$ after the wind shift provide an estimated value of $\partial v / \partial z$ of 2.0 $\times 10^{-2} \mathrm{~s}^{-1}$ which agrees with the observed magnitude of the horizontal vorticity along a typical sea breeze front [25]. Therefore, the estimated $\zeta$ with the given assumptions in this case is approximately $0.2 \mathrm{~s}^{-1}$ which compares very well with the modeled vorticity $\left(\sim 0.2-0.3 \mathrm{~s}^{-1}\right)$ of Jenkins et al. [23]. This is most likely because the numerical setup has several similarities with this field experiment such as grass fuels and the presence of environmental vertical wind shear. One major difference between the simulations and our experiment is that the simulation was made without a density current representing the sea breeze.

Based on the tower measurements, the sea breeze arrival is clearly evident by 12:43 PDT when the wind direction shifted to north and northeast (Figure 9(b)) and the relative humidity $(\mathrm{RH})$ sharply increased $5 \%$ over a $1 \mathrm{~min}$ period (Figure 9(c)). Meteorological conditions were also measured at the downwind site (Figure 2) on the portable RAWS station. Surface pressure at this site dropped $\sim 0.2 \mathrm{mb}$ at 12:38 PDT and recovered by 12:48 PDT (Figure $9(\mathrm{~d})$ ). We speculate that the drop in pressure occurred not only at the RAWS site, but in the whole lower valley and is due to the development of a convergence zone that formed ahead of the sea breeze front as it entered the valley and interacted with the opposing valley wind [20]. At the same time the pressure recovery occurs, the wind direction shifted to a more northerly direction that we interpret as the dominant sea breeze direction in the valley. In addition, $\mathrm{RH}$ increased further, which indicates that the sea breeze front pushed further into the valley.

The transition between two wind regimes can lead to hazardous conditions for fire fighters due to the generation of unpredictable fire behavior. As observed in this case, the fire whirl appeared approximately $10 \mathrm{~m}$ away from the fire fighters (Figure 6) and only $10 \mathrm{~s}$ after the wind reversal occurred. The video and time-lapse photos also showed fire fighters running away from the fire whirl indicating their sense of urgency and safety during this event. Although the period of interaction between the sea breeze front and the fire may be relatively short, the impact on fire behavior may be significant $[15,21]$. Jenkins et al. [23] point out that a background low-level vertical shear generated by a wind reversal with height is capable of generating extreme grassfire behavior and fire spread. Furthermore, a fire whirl event was observed in a canyon of the Santa Ana Mountains by Schroeder [26] who emphasized the potential for extreme fire behavior during a transition period between two wind regimes. Countryman [27] found that certain geographic locations such as the lee side of ridge tops are favorable for two opposing currents to meet, and thus major fire whirl activity tends to occur frequently in these locations. Mountain valleys are a favorable location for the interaction of two wind regimes that differ in temperature and direction such as the wind reversal of valley winds [18]. It is likely that in this case, the narrow Hall's Valley sets up an ideal environment for the interaction of the sea breeze and upvalley winds in the afternoon, as the elevated topography of the Diablo Range retarded the onset of the sea breeze preventing its penetration over the terrain until the up-valley flow was well established.

3.3. Turbulence Characteristics. This section investigates the near-surface turbulence structure measured during the sea breeze break-in, the period associated with the fire whirl development, and the period the FFP occurred. One variable often used to quantify atmospheric turbulence is the turbulence kinetic energy (TKE). TKE is defined as the kinetic energy per unit mass associated with the amount of ambient wind shear present within an atmospheric layer [28]. Following Stull [29], the TKE is found by the sum of the velocity variances $u, v$, and $w$

$$
\mathrm{TKE}=0.5\left(\overline{u^{\prime 2}}+\overline{v^{\prime 2}}+\overline{w^{\prime 2}}\right) .
$$

The variance of each wind velocity component is calculated from the processed $10 \mathrm{~Hz}$ sonic anemometer data which have 


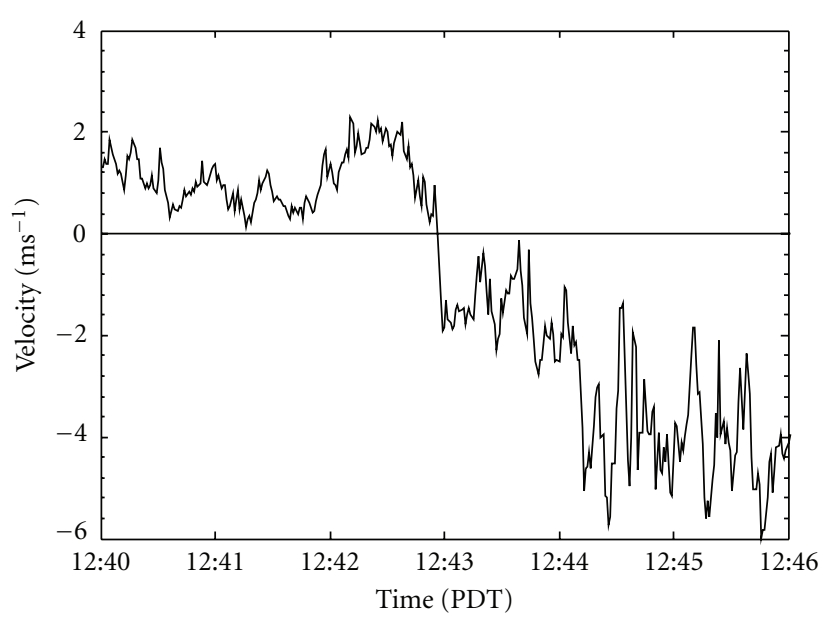

(a) up-valley

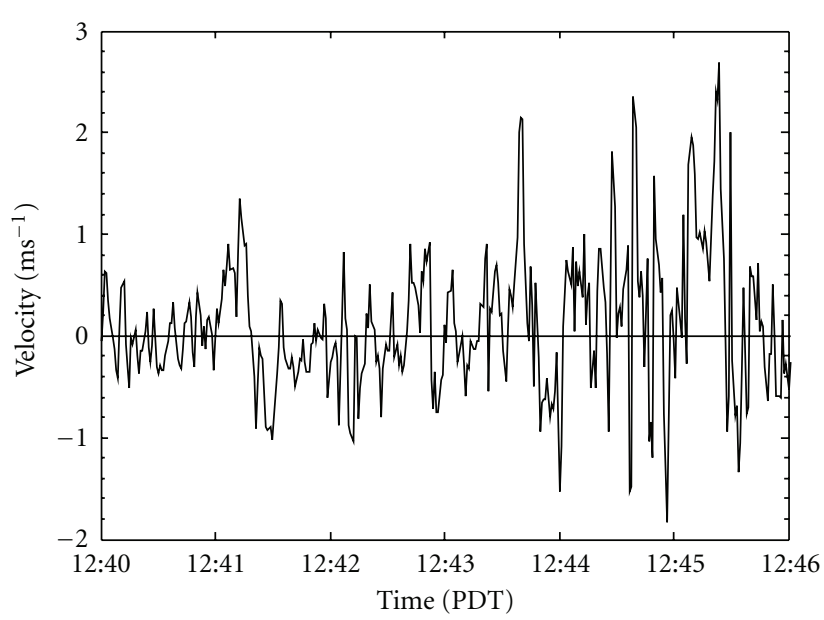

(b) vertical

FIGURE 8: A time series of $1 \mathrm{~Hz}$ (a) along valley and (b) vertical velocity, $w$, observed at the interior tower. Positive along-valley wind velocities in (a) indicate up-valley direction.

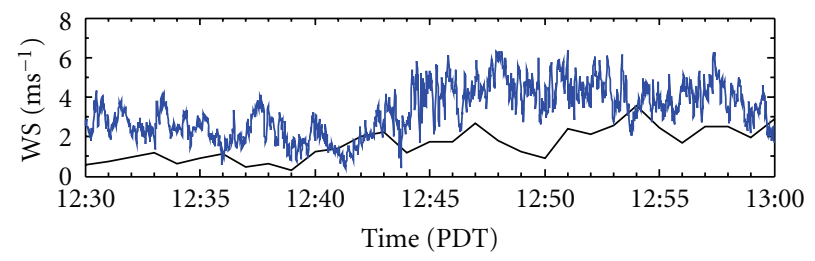

(a)

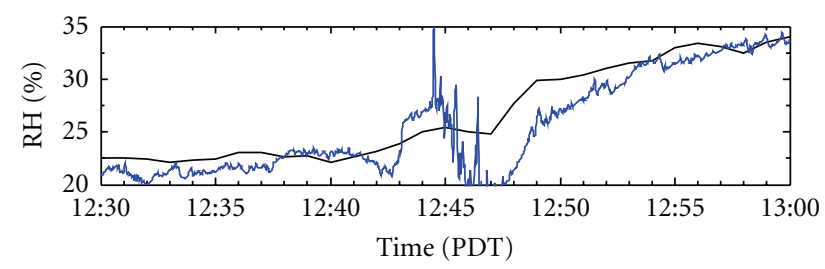

(c)

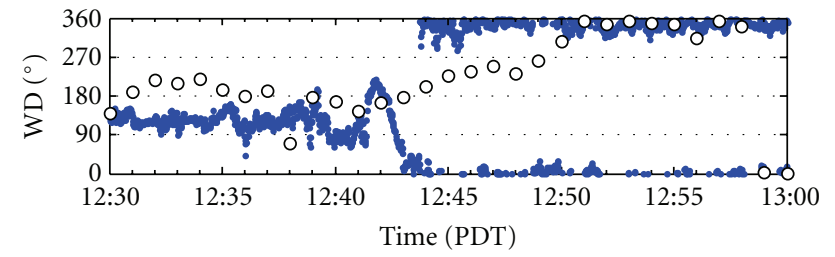

(b)

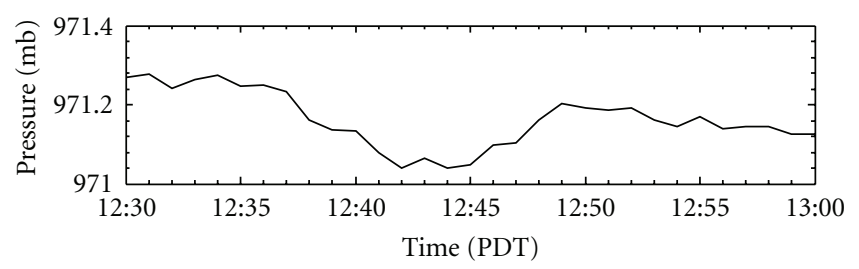

(d)

FIGURE 9: Time series of (a) wind speed, (b) wind direction, (c) relative humidity (RH), and (d) pressure measured at the interior tower and downwind RAWS between 12:30 and 13:00 PDT. The tower data and RAWS data are averaged over $1 \mathrm{~s}$ and $1 \mathrm{~min}$, respectively. The blue represents the interior tower and the black represents the RAWS.

been high-pass filtered to remove any spikes. Additionally, the time series of the velocity components has been tiltcorrected [30] in order to rotate the components into the mean flow and remove any bias of the anemometer mounting not being precisely level during deployment. The turbulent components of the variables, $u^{\prime}, v^{\prime}, w^{\prime}$, and $T_{s}^{\prime}$ are calculated by removing the mean from the instantaneous data. We have selected an averaging period of $10 \mathrm{~min}$ to calculate the perturbations, while the averaging period chosen for the variance and TKE was $30 \mathrm{~s}$ which allowed the turbulent fluxes associated with the FFP and fire whirl to be isolated. Another key turbulent statistic is the sensible heat flux, $h_{s}=\rho c_{p} \overline{w^{\prime} T_{s}^{\prime}}$, where the term $w^{\prime} T_{s}^{\prime}$ is the covariance between the vertical velocity perturbation and sonic temperature perturbation, $\rho$ is the density of air, and $c_{p}$ is the heat capacity of air at constant pressure. The sensible heat flux was averaged over $1 \mathrm{~min}$ and allows us to also determine the timing of smoke plume and FFP at the tower.

Figure 10 shows a time series of the TKE and sensible heat flux (Figure 10(a)) and the individual velocity variances (Figures 10(b)-10(d)). Although there is no increase in TKE between 12:43 and 12:44 PDT when the fire whirl was observed, a large increase in TKE is clearly evident prior to 12:43 PDT in Figure 10(a). The increase in TKE begins at 12:40 PDT with the value of $5.2 \mathrm{~m}^{2} \mathrm{~s}^{-2}$, compared to prior ambient background value of $<1.5 \mathrm{~m}^{2} \mathrm{~s}^{-2}$. The peak TKE occurs at 12:42 PDT with the value of $10.4 \mathrm{~m}^{2} \mathrm{~s}^{-2}$ before sharply dropping to $1.4 \mathrm{~m}^{2} \mathrm{~s}^{-2}$. It should be noted that the TKE started increasing three minutes before the relative humidity started increasing. We hypothesize that the interaction of the sea breeze front and up-valley flow started at 12:40 PDT, but the relative humidity increase was 


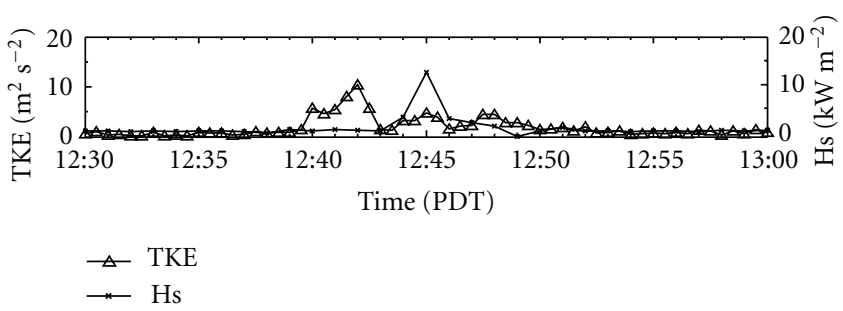

(a)

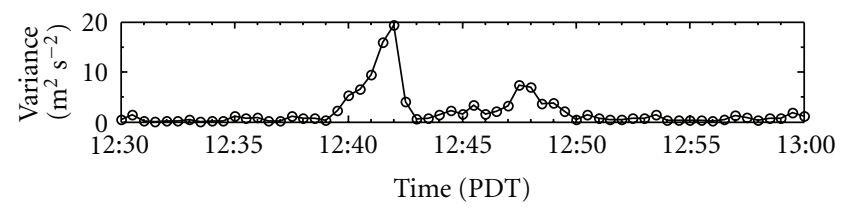

$v^{\prime 2}$

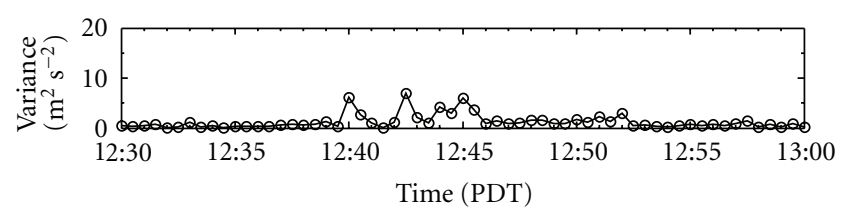

$-u^{\prime 2}$

(b)

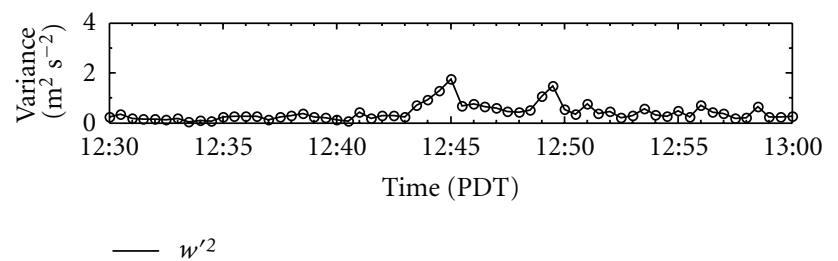

(d)

FiguRE 10: Time series of (a) $30 \mathrm{~s}$ averaged turbulence kinetic energy and 1 min averaged sensible heat flux, (b), (c), and (d) $30 \mathrm{~s}$ averaged $u$, $v$, and $w$ velocity component perturbation variances, respectively.

not detected by the humidity sensor due to the mixing of the air between the two flows. The second and third TKE peaks (5.0 and $4.5 \mathrm{~m}^{2} \mathrm{~s}^{-2}$ ) that occur at 12:45 and 12:47 PDT, respectively, are the turbulence associated with the FFP. Although the wind flow around the flaming area is known to be highly turbulent [14], observations indicate that the greatest TKE measured was caused by wind shear associated with the sea breeze arrival and is two times greater in magnitude than the TKE generated by the passing fire front. The FFP is indicated by the maximum in sensible heat flux $\left(\sim 12.5 \mathrm{~kW} \mathrm{~m}^{-2}\right)$ that occurred at 12:45 PDT. The source of the turbulence kinetic energy generation is determined by diagnosing the velocity variances separately.

The large increase in TKE between 12:40 to 12:43 PDT was dominated by $\overline{v^{\prime 2}}$ which was nearly $20 \mathrm{~m}^{2} \mathrm{~s}^{-2}$ (Figure 10(c)), while both $\overline{u^{\prime 2}}$ and $\overline{w^{\prime 2}}$ remained below $10 \mathrm{~m}^{2} \mathrm{~s}^{-2}$. Since the $v$ variance represents north-south component of the turbulence intensity, it is most likely that the observed turbulence was caused by the wind shear generated between the southerly up-valley flow and northerly sea breeze. We also believe this shear to be responsible for setting up the horizontally rotating column of the air ahead of fire front creating the observed vorticity and resulting fire whirl. The observed increase in $\overline{w^{\prime 2}}$ at 12:45:00 (Figure 10(d)) corresponds to the maximum in sensible heat flux. The second peak in $\overline{w^{\prime 2}}$ (at 12:49:30 PDT) suggests an impact from smoldering after the FFP occurred. The maximum $w$ variance of $1.5 \mathrm{~m}^{2} \mathrm{~s}^{-2}$ was much lower than the $v$ component suggesting that wind shear played a larger role on the local turbulence than the sensible heat flux generated by the fire front. Comparing these results with other grass fire experiments (e.g., FireFlux, [14]) indicates that the values observed during this experiment are much lower than those reported by Clements et al. [14] who measured peak $w$ variances $>5 \mathrm{~m}^{2} \mathrm{~s}^{-2}$. This can be attributed to the fact that the heat flux observed during FireFlux was twice as large as observed in the present study.
The reason for this can be simply due to a higher observed fuel loading measured during FireFlux [13].

3.4. Fire Intensity. In previous studies, the fire intensity has been used primarily to determine resulting fire behavior. However, in order to determine the role the fire had on the development of the fire whirl, the heat release or fire intensity must be quantified. Byram [5] and Graham [6] associated fire whirl occurrence with large fire events or high intensity fires. Model simulations by Heilman and Fast [31] also showed that the roll vortices become more vigorous with increased surface temperature. Although the tower was $\sim 35 \mathrm{~m}$ away from the fire front when the fire whirl occurred, we estimate the amount of heat supplied at the fire front to tilt the horizontally rotating column by assuming the heat flux measured at the tower at 12:46:30 PDT is nearly the same during the fire whirl formation (12:43:10 PDT). A time series of the $1 \mathrm{~Hz}$ total heat flux (Hukseflux, SBG01 sensor) presented in Figure 11(a) shows that the maximum in total heat flux of $\sim 10 \mathrm{~kW} \mathrm{~m}^{-2}$ as the fire front approached and passed the tower. The instantaneous total heat flux of $12.3 \mathrm{~kW} \mathrm{~m}^{-2}$ (not shown) is nearly the same magnitude as the $1 \mathrm{~min}$ averaged sensible heat flux of $12.5 \mathrm{~kW} \mathrm{~m}^{-2}$ (Figure 10(a)). We assume that the total heat flux present during the fire whirl formation is close to that measured at the tower given the uniform fuel type and flame lengths observed with the time-lapse camera. The total heat flux measured during the FFP of this particular grass fire was much lower compared to the radiant heat flux of $290 \mathrm{~kW} \mathrm{~m}^{-2}$ measured during a crown fire [32] and lower than the maximum total heat flux of $112 \mathrm{~kW} \mathrm{~m}^{-2}$ during a shrubland fire [33]. Fire intensity during prescribed burns is usually much lower for ecological management purposes (see Section 2.4). Nonetheless, a small-scale fire whirl formed very close to the fire fighters as seen in the photos in Figure 6. Although no fire fighters were injured during the event due to their safe distance from the fire whirl, it should be 


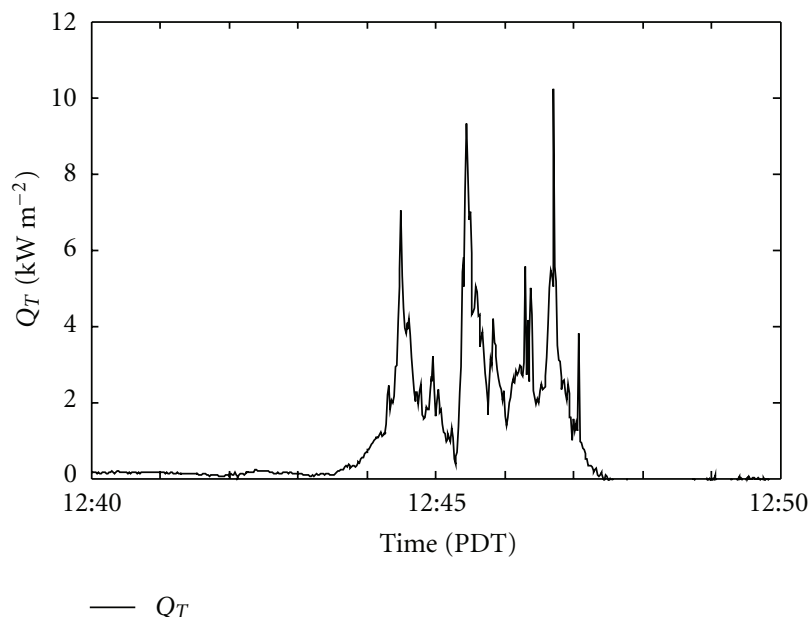

(a)

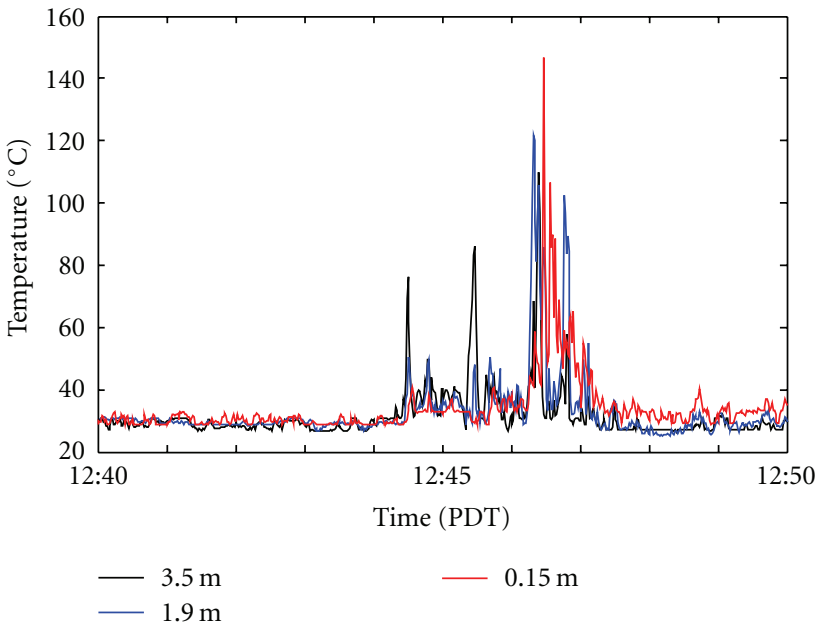

(b)

FIGURE 11: Time series of 1-s averaged (a) total heat flux, $Q_{T}$, and (b) thermocouple temperatures, $T_{c}$, at different levels on the interior tower.

emphasized that the potential for unpredictable fire whirl formation during low-intensity, controlled burns exists.

Near-flame plume temperatures were measured using the thermocouple array as the fire front passed the tower. Unlike the radiative heat flux that is measured from the flaming front, the observed plume temperatures (Figure 11(b)) can be used to directly quantify the plume heating rates [34] and timing of the FFP. An observed increase in the temperature at $3.5 \mathrm{~m}$ AGL between 12:44 and 12:46 PDT was caused by the tilted smoke plume ahead of the fire front impinging on the tower. The two lower thermocouples indicated smaller temperature increases of $150^{\circ} \mathrm{C}$ and $120^{\circ} \mathrm{C}$ at $0.15 \mathrm{~m}$ and $1.9 \mathrm{~m}$, respectively, which are caused by the near-surface advection from the approaching flaming front. The observed temperature increase due to the plume is much lower than those observed by Clements [34] during the FireFlux experiment.

3.5. Assessment of Convective Froude Number. In order to determine the role fire intensity has on resulting fire behavior and the resulting atmospheric circulations, the convective Froude number is analyzed. The convective Froude number, $F_{c}$, is a measure of the ratio of the kinetic energy of the air over the fire to the sensible heat flux provided by the fire $[12,35]$. The $F_{c}$ is useful as a controlling parameter to determine the type and level of fire-atmosphere coupling. For instance, Clark et al. [12] hypothesized that a small $F_{c}^{2}$ that is indicative of strong coupling between the air and fire may be a necessary condition for a blowup fire [5] to occur. The $F_{c}$ is a nondimensional number given by

$$
F_{c}^{2}=\frac{\left(U-S_{f}\right)^{2}}{g(\langle\Delta \theta\rangle /\langle\theta\rangle) W_{f}},
$$

where $U$ and $S_{f}$ represent the wind speed and rate of spread, respectively, $W_{f}$ is the fire line width, $\theta$ is temperature, $\Delta \theta / \theta$ the convective buoyancy, and $g$ acceleration due to gravity.
The bracketed temperatures are the average for the period during the FFP.

The tower data and time-lapse photography allow an estimate of the variables necessary to calculate $F_{c}$. Prior to $12: 42 \mathrm{PDT}$, when the up-valley wind was observed and the fire front was spreading against the wind, $F_{c}$ was calculated using an average up-valley wind speed $U_{f}$ of $2.2 \mathrm{~ms}^{-1}$ between 12:39 and 12:40 PDT, a forward fire spread rate $S_{f}$ of $0.5 \mathrm{~ms}^{-1}$, and the depth of the flaming fire front $W_{f}$ of $4 \mathrm{~m}$. Both $S_{f}$ and $W_{f}$ were estimated using the $6.7 \mathrm{~m}$ tower in the time lapse photos as a reference length and scaling the distances of the fire front spread over time and the depth of the flame in the photos. For instance, we used two photos to estimate that the fire front spread $6 \mathrm{~m}$ in $12 \mathrm{~s}$ from 12:40 PDT. The flame depth was estimated from a photo taken at 12:39:28 PDT (not shown). The measured thermocouple temperature profile (Figure 11(b)) provides the mean temperature anomaly, $\Delta \theta$, over the fire front. A mean air temperature of the area is obtained from the average sonic temperature. All the variables used to calculate $F_{c}$ are listed in Table 1.

The results show that prior to 12:42 PDT, when upvalley winds were present, $F_{c}<1$ indicating that buoyancy is the dominant mechanism and both the atmosphere and fire were essentially coupled. When the ambient wind speed increased to $4.1 \mathrm{~ms}^{-1}$ due to the sea breeze arrival, $F_{c}$ became greater than one (Table 1). It appears $F_{c}$ is less relevant to the low-level environmental shear generated by the interaction of topography and mesoscale flow and therefore, the use of $F_{c}$ itself may not be suitable for predicting the fire whirl potential in this particular case. Sullivan [36] recently re-examined $F_{c}$ and concluded that it is not reflected in observed fire behavior, and our result is consistent with Sullivan's [36] findings on limited usefulness of the convective Froude number for the assessment of the fire whirl potential. The large increase in TKE observed during the valley wind reversal in this study suggests that such a variable may be either used independently or could potentially be 
TABle 1: Numbers used to calculate the convective Froude number in two cases: up-valley wind case (1st row) and sea breeze wind case (2nd row). $U_{f}$ represents ambient wind speed, $U_{f}$ forward rate of fire spread, $g$ gravity, $\theta$ potential temperature, $\Delta \theta$ mean perturbation temperature near the region of intense heating, $W_{f}$ fire line depth, and $F_{c}$ convective Froude number.

\begin{tabular}{lcccccc}
\hline $\begin{array}{l}U_{f} \\
\left(\mathrm{~ms}^{-1}\right)\end{array}$ & $\begin{array}{c}S_{f} \\
\left(\mathrm{~ms}^{-1}\right)\end{array}$ & $\begin{array}{c}g \\
\left(\mathrm{~ms}^{-2}\right)\end{array}$ & $\begin{array}{c}\theta \\
(\mathrm{K})\end{array}$ & $\begin{array}{c}\Delta \theta \\
(\mathrm{K})\end{array}$ & $\begin{array}{c}W_{f} \\
(\mathrm{~m})\end{array}$ & $F_{c}^{2}$ \\
\hline 2.2 & 0.5 & 9.8 & 301 & 36 & 4 & 0.61 \\
4.1 & 0.75 & 9.8 & 299 & 36 & 5.5 & 1.73 \\
\hline
\end{tabular}

combined with $F_{c}$ as a supplemental parameter to assess whether a fire whirl is more likely. Heilman and Bian [28] showed that the product of the Haines Index (HI) and nearsurface TKE $(\mathrm{HI} \times \mathrm{TKE})$ is a useful parameter to indicate whether atmospheric conditions are highly conductive to large fire development.

\section{Summary and Conclusions}

This paper presents observations made of the evolution of a small fire whirl that formed during a prescribed grass fire conducted in a narrow mountain valley. The meteorological conditions and heat release measured at a tower located in the vicinity of the fire were analyzed in an attempt to determine what caused the observed fire whirl to form. Key findings from this study include the following.

(i) The fire whirl occurred with the arrival of the sea breeze front in a narrow valley that was initially dominated by a daytime up-valley flow. The two opposing ambient flows produced low-level, vertical wind shear. We hypothesize that the fire whirl was caused by the interaction of the wind shear with the fire front. The fire whirl formed at the fire front and was advected behind the fire front during its evolution. The advection of the vorticity was caused by either the up-valley wind or by the formation of a pressure perturbation across the fire line.

(ii) Estimated vorticity generated by the interaction of the wind shear and the fire front was $\sim 0.2 \mathrm{~s}^{-1}$ which falls in range of magnitude simulated by Jenkins et al. [22] during an ideal grass fire.

(iii) The turbulence kinetic energy of the ambient wind shear $\left(\sim 10.4 \mathrm{~m}^{2} \mathrm{~s}^{-2}\right)$, generated by the wind reversal, was two times greater in magnitude than turbulence generated by the buoyancy induced by the fire front. Therefore, ambient wind shear is most likely the dominant mechanism for fire whirl development in this case.

(iv) The sensible and total heat flux measured during the fire front passage showed that the fire whirl formed during a low intensity $\left(\sim 12 \mathrm{~kW} \mathrm{~m}^{-2}\right)$, controlled grass fire.

(v) The convective Froude number, $F_{c}$, was $<1$ when upvalley winds were present in the valley. During this time the fire was backing into the wind, buoyancy was driving the fire behavior, and the flow and fire were coupled with each other. As the wind speed increased due to the sea breeze surge, $F_{c}$ became $>1$, which is a sign of the decreased level of the coupling. However, the convective Froude number itself may not be sufficient for fire whirl prediction because it does not take account for the near-surface turbulence generated by environmental wind shear.

(vi) For fire management, a sudden reversal in mesoscale winds or even a diurnal, valley wind shift should be carefully monitored since the presence of two opposing flows is a favorable condition for the development of fire whirls. Although the wind shift may be brief and localized, the potential for extreme fire behavior may be high and thus should always be considered a watch out situation.

The importance of the sudden wind shift and nearsurface TKE is therefore emphasized in terms of the potential for fire whirl development. Similar scenarios of wind reversals are possible in complex terrain where the valley winds transition from nocturnal drainage flows to daytime up-valley winds that can coincide with wildland fire. Additionally, further development of surface wind prediction in complex terrain [37] may become beneficial not only for fire spread forecasting over complex terrain but also for specifying locations prone to valley-flow convergence that can cause sudden wind shifts. The interaction of wildfires with valley-scale meteorology is not well understood and remains a topic to be investigated with both observational studies and coupled fire-atmosphere modeling systems.

\section{Acknowledgments}

This research is supported by a Joint Venture Research Agreement with the USDA Northern Research Station no. 07-JV-11242300-073. The authors thank the Cal Fire Santa Clara Unit and in particular Battalion Chief Dave McLean for conducting the prescribed burn and for accommodating their research objectives. They also acknowledge the Santa Clara County Department of Parks and Recreation for the use permit. They also want to acknowledge the stimulating discussions they had with Jason Forthofer from the USDA Forest Service FireLab in Missoula, MT and Professor Jim Steenburgh from the University of Utah. Finally, They thank the three anonymous reviewers for their insightful comments which greatly improved the clarity and overall quality of this paper.

\section{References}

[1] J. Forthofer, M. Shannon, and B. Butler, "Investigating causes of large scale fire whirls using numerical simulation," in Proceedings of the 80th Symposium on Fire and Forest Meteorology, p. 4, Kalispell, Mont, USA, October 2009.

[2] H. E. Graham, "A fire-whirlwind of tornadic violence," Fire Control Note, pp. 22-24, 1952. 
[3] C. M. Countryman, Fire Whirls...Why, When, and Where, USFS Pacific Southwest Research Station, Berkeley, Calif, USA, 1971.

[4] M. E. Umscheid, J. P. Monteverdi, and J. M. Davies, "Photographs and analysis of an unusually large and long-lived firewhirl," The Electronic Journal of Severe Storms Meteorology, vol. 1, no. 2, 2006.

[5] G. M. Byram, "Atmospheric conditions related to blowup fires," Station Paper 35, USFS Southeastern Forest Experiment Station, Asheville, NC, USA, 1954.

[6] H. E. Graham, "Fire-whirlwind formation as favored by topography and upper winds," Fire Control Note, pp. 20-24, 1957.

[7] A. R. Pirsko, L. M. Sergius, and C. W. Hickerson, Causes and Behavior of a Tornadic Fire-Whirlwind, USFS Pacific Southwest Forest and Range Experiment Station, Berkeley, Calif, 1965.

[8] D. A. Haines and L. J. Lyon, "Horizontal roll vortices in complex terrain," Fire Management Notes, vol. 51, no. 2, pp. 15-17, 1990.

[9] W. E. Heilman, "Simulations of buoyancy-generated horizontal roll vortices over multiple heating lines," Forest Science, vol. 40, pp. 601-617, 1994.

[10] R. N. Meroney, "Fire whirls, fire tornadoes and firestorms: physical and numerical modeling," in Proceedings of the International Workshop on Physical Modelling of Flow and Dispersion Phenomena (PHYSMOD '03), Prato, Italy, 2003.

[11] T. F. Fric and A. Roshko, "Vortical structure in the wake of a transverse jet," Journal of Fluid Mechanics, vol. 279, pp. 1-47, 1994.

[12] T. L. Clark, M. A. Jenkins, J. L. Coen, and D. R. Packham, “A coupled atmosphere-fire model: role of the convective froude number and dynamic fingering at the fireline," International Journal of Wildland Fire, vol. 6, no. 4, pp. 177-190, 1996.

[13] C. B. Clements, S. Zhong, S. Goodrick et al., "Observing the dynamics of wildland grass fires: fireFlux-a field validation experiment," Bulletin of the American Meteorological Society, vol. 88, no. 9, pp. 1369-1382, 2007.

[14] C. B. Clements, S. Zhong, X. Bian, W. E. Heidman, and D. W. Byun, "First observations of turbulence generated by grass fires," Journal of Geophysical Research D: Atmospheres, vol. 113, no. 22, 2008.

[15] D. E. Hanley, P. Cunningham, and S. L. Goodrick, "Interaction between a wildfire and a sea breeze front: case study and idealized numerical simulations," Earth Science Satellite Remote Sensing, submitted.

[16] N. R. Williams, "Development of dust whirls and similar small scale vortices," Bulletin of the American Meteorological Society, vol. 26, pp. 106-117, 1948.

[17] H. B. Bluestein, C. C. Weiss, and A. L. Pazmany, "Doppler radar observations of dust devils in Texas," Monthly Weather Review, vol. 132, no. 1, pp. 209-224, 2004.

[18] C. D. Whiteman, "Observations of thermally developed wind systems in mountainous terrain," Atmospheric Processes over Complex Terrain, Meteorological Monographs, no. 45, pp. 5-42, 1990.

[19] G. Rampanelli, D. Zardi, and R. Rotunno, "Mechanisms of upvalley winds," Journal of the Atmospheric Sciences, vol. 61, no. 24, pp. 3097-3111, 2004.

[20] J. E. Simpson, Sea Breeze and Local Winds, Cambridge University Press, New York, NY, USA, 1994.

[21] P. Cunningham, "Idealized numerical simulations of the interactions between buoyant plumes and density currents," Journal of the Atmospheric Sciences, vol. 64, no. 6, pp. 2105$2115,2007$.
[22] M. A. Jenkins, T. Clark, and J. Coen, "Coupling atmospheric and fire models," in Forest Fire: Behavior and Ecological Effects, E. A. Johnson and K. Miyanishi, Eds., pp. 257-302, Academic Press, New York, NY, USA, 2001.

[23] M. A. Jenkins, R. Sun, S. K. Krueger, J. J. Charney, and M. A. Zulauf, "Effect of vertical wind shear on grassfire evolution," in Proceedings of the 7th Symposium of Forest and Fire Meteorology, Bar Harbor, Me, USA, October 2007.

[24] W. E. Heilman, "Atmospheric simulations of extreme surface heating episodes on simple hills," International Journal of Wildland Fire, vol. 2, no. 3, pp. 99-114, 1992.

[25] N. T. Atkins, R. M. Wakimoto, and T. M. Weckwerth, "Observations of the sea-breeze front during CaPE. Part II: dual-Doppler and aircraft analysis," Monthly Weather Review, vol. 123, pp. 944-969, 1995.

[26] M. J. Schroeder, "Down-canyon afternoon winds," Bulletin of the American Meteorological Society, vol. 42, no. 8, pp. 527$542,1961$.

[27] C. M. Countryman, "Mass fires and fire behavior," U. S. Forest Service Research Paper, PSW-19, Pacific Southwest Forest and Range Experiment Station, Berkeley, Calif, USA, 1964.

[28] W. E. Heilman and X. Bian, "Turbulent kinetic energy during wildfires in the north central and north-eastern US," International Journal of Wildland Fire, vol. 19, no. 3, pp. 346$363,2010$.

[29] R. B. Stull, An Introduction to Boundary Layer Meteorology, Kluwer Academic, Boston, Mass, USA, 1988.

[30] J. M. Wilczak, S. P. Oncley, and S. A. Stage, "Sonic anemometer tilt correction algorithms," Boundary-Layer Meteorology, vol. 99, no. 1, pp. 127-150, 2001.

[31] W. E. Heilman and J. D. Fast, "Simulation of horizontal roll vortex development above lines of extreme surface heating," International Journal of Wildland Fire, vol. 2, no. 2, pp. 55-68, 1992.

[32] J. D. Cohen, "Relating flame radiation to home ignition using modeling and experimental crown fires," Canadian Journal of Forest Research, vol. 34, no. 8, pp. 1616-1626, 2004.

[33] F. Morandini and X. Silvani, "Experimental investigation of the physical mechanisms governing the spread of wildfires," International Journal of Wildland Fire, vol. 19, no. 5, pp. 570$582,2010$.

[34] C. B. Clements, "Thermodynamic structure of a grass fire plume," International Journal of Wildland Fire, vol. 19, no. 7, pp. 895-902, 2010.

[35] G. M. Byram, "Combustion of forest fuels," in Forest Fire: Control and Use, A. A. Brown and K. P. Davis, Eds., pp. 155182, McGraw-Hill, New York, NY, USA, 1959.

[36] A. L. Sullivan, "Convective Froude number and Byram's energy criterion of Australian experimental grassland fires," in Proceedings of the 31st International Symposium on Combustion, pp. 2557-2564, August 2006.

[37] J. M. Forthofer, Butler B. W., K. S. Shannon, M. A. Finney, L. S. Bradshaw, and R. Stratton, "Predicting surface winds in complex terrain for use in fire spread models," in Proceedings of the 5th Symposium on Fire and Forest Meteorology and 2nd Forest Fire Ecology and Fire Management Congress, p. 4, Orlando, Fla, USA, November 2003. 

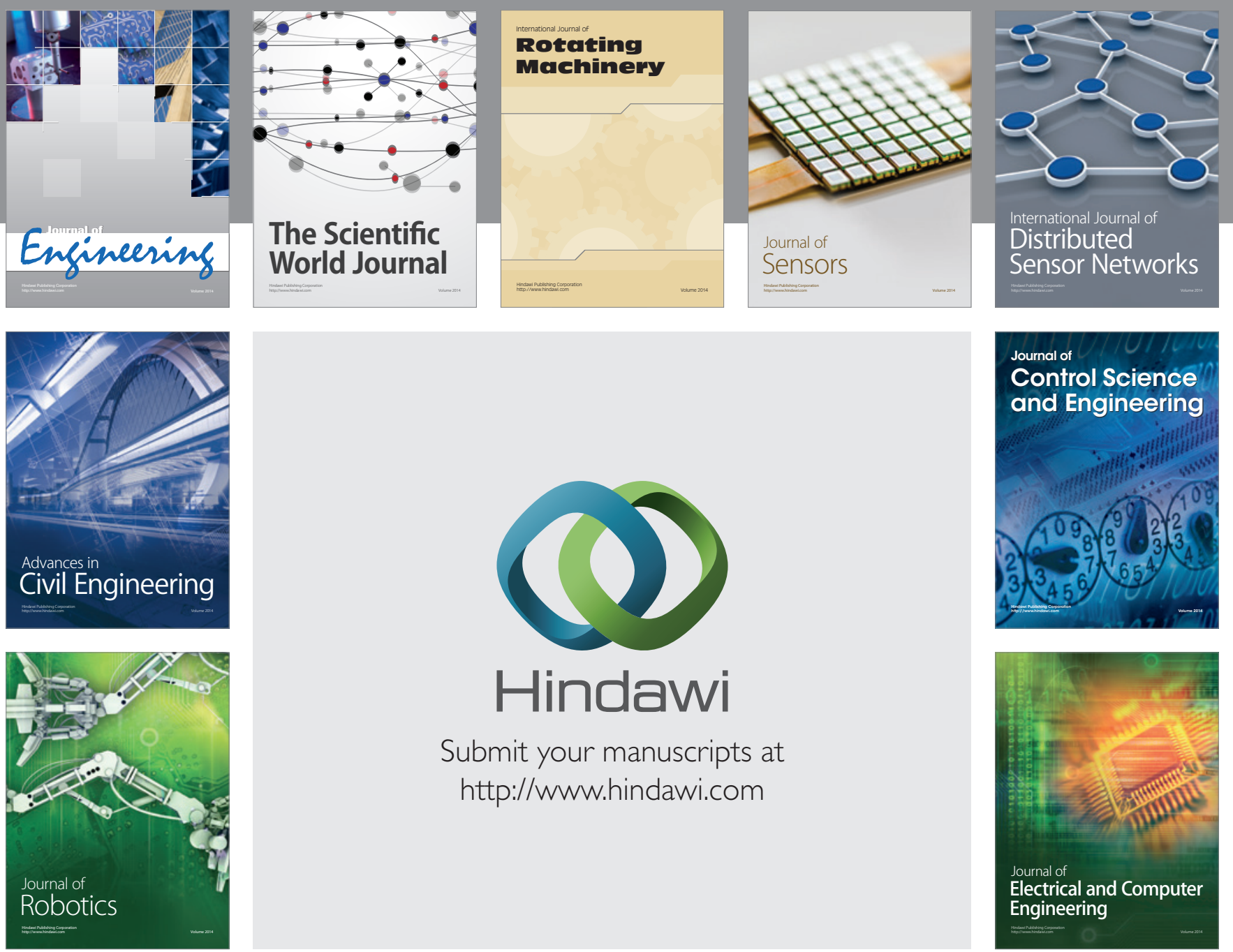

Submit your manuscripts at

http://www.hindawi.com
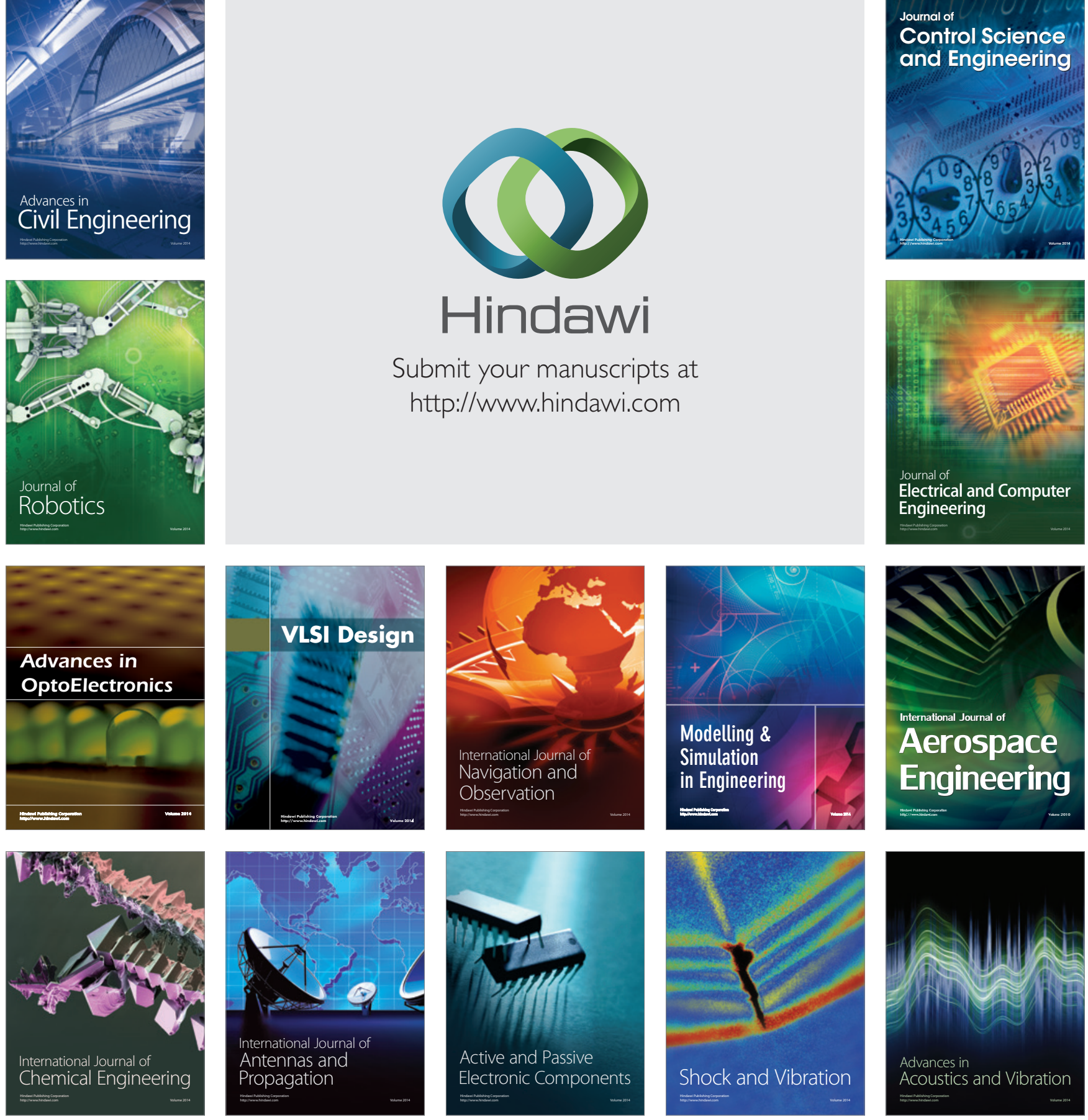